\title{
REFLEXÕES ACERCA DAS MULTIMODALIDADES NAS PRÁTICAS DE ENSINO APRENDIZAGEM ${ }^{1}$
}

\author{
REFLECTIONS ON MULTIMODALITIES IN PRACTICES TEACHING LEARNING
}

\author{
Clarice Rosa Machado ${ }^{2}$, Carla da Silva Ribeiro ${ }^{3}$ e Taís Steffenello Ghisleni ${ }^{4}$
}

\section{RESUMO}

O desenvolvimento tecnológico e das mídias digitais resultaram em transformações nos meios de comunicação e no fluxo de informação. Isso gerou impacto social e alterou as relações humanas e as práticas de ensino. No presente estudo têm-se por objetivo refletir acerca das contribuições do ensino de multimodalidades para a prática docente e apresentar um recorte do planejamento didático "Meio Ambiente em Jogo", proposto na disciplina de Linguagens e Tecnologias aplicadas ao Ensino, do Mestrado Acadêmico em Ensino de Humanidades e Linguagens, da Universidade Franciscana. Também será apresentada uma aplicação prática, desenvolvida em uma disciplina do Mestrado e Ensino de Humanidades e Linguagens da Universidade Franciscana. A metodologia utilizada para o trabalho apresenta abordagem qualitativa, de cunho bibliográfico e descritivo. Diante das transformações tecnológicas que repercutem na prática docente, o professor precisa entender as contribuições que os usos de recursos multimodais oferecem para o processo de ensino e aprendizagem, rompendo com o modelo tradicional em que o professor era considerado o detentor do saber.

Palavras-chave: Ensino Aprendizagem; Prática docente; Tecnologia.

\section{ABSTRACT}

Technological and digital media development have resulted in transformations in the media and the flow of information. This generated social impact and altered human relations and teaching practices. This study aims to reflect on the contributions of multimodality teaching to teaching practice and to present an section of the didactic planning "Environment at Stake", proposed in the discipline of Languages and Technologies applied to Teaching, of the Academic Master in Teaching of Humanities and Languages, of the Franciscan University. A practical application will also be presented, developed in a discipline of the Master's degree and Teaching of Humanities and Languages of the Franciscan University. The methodology used for the work presents a qualitative, bibliographic and descriptive approach. Given the technological transformations that have repercussions on teaching practice, the teacher needs to understand the contributions that the uses of multimodal resources offer to the teaching and learning process, breaking with the traditional model in which the teacher was considered the holder of knowledge.

Keywords: Teaching Learning; Teaching practice; Technology.

\footnotetext{
1 Artigo desenvolvido na disciplina de Linguagens e Tecnologias aplicada ao ensino no Mestrado em Ensino de Humanidades e Linguagens da Universidade Franciscana (UFN).

2 Licenciada em Filosofia. Mestra em Ensino de Humanidades e Linguagens pela Universidade Franciscana. E-mail: clarice.r.machado@gmail.com

3 Pedagoga. Mestra em Ensino de Humanidades e Linguagens pela Universidade Franciscana. E-mail: carlazem@gmail.com 4 Doutora em Comunicação. Professora do Mestrado em Ensino de Humanidades e Linguagens da Universidade Franciscana. E-mail: taisghisleni@yahoo.com.br
} 


\section{INTRODUÇÃO}

A vida dos seres humanos está associada ao processo de comunicação e o aprimoramento desta acompanha a própria evolução humana. Braga e Calazans (2001, p. 14) afirmam que a comunicação é "conatural" ao ser humano. E só com a comunicação é que existe a sociedade, a comunidade. Somado à essa afirmação, Angeloni (2010) diz que é a partir do relacionamento com o mundo que o homem aperfeiçoa sua capacidade comunicativa, envolvendo sons, imagens, palavras, os textos verbais e não-verbais interagem e contribuem para a representação oral e escrita das ideias. Neste sentido, a linguagem ocupa um lugar central na vida do ser humano, pois é a forma como as pessoas se comunicam e se relacionam com o outro, por exemplo, linguagem subjetiva, interpessoal. A linguagem pode ser classificada de várias maneiras, entre elas podemos citar a linguagem oral, corporal, a maneira de se vestir, entre outras. Mas, independentemente da classificação, a linguagem, conforme Berger e Luckmann (2003), simboliza as experiências vividas, dotadas de significados, sentimentos compartilhados e pessoais dos sujeitos.

A partir do desenvolvimento tecnológico e das mídias digitais ocorreram várias transformações nos meios de comunicação e isso alterou o fluxo de informação, gerou impacto social alterou tanto as relações humanas quanto as práticas de ensino. As alterações nas relações humanas podem ser percebidas, por exemplo, na criação de redes sociais digitais, nas quais as pessoas não precisam estar mais face a face para interagirem em tempo real (THOMPSON, 1998). No que diz respeito às práticas de ensino aprendizagem, os avanços tecnológicos modificaram as metodologias de ensino, rompendo com o modelo tradicional no qual o professor era considerado o detentor do saber. O grande desafio da educação está em superar a visão fragmentada e de reprodução de conhecimento para a produção de conhecimentos pertinentes a vida em sociedade (BEHRENS, 2011).

Diante do exposto, esse estudo tem por objetivo refletir acerca das contribuições do ensino de multimodalidades para a prática docente e apresentar um recorte do planejamento didático "Meio Ambiente em Jogo", proposto na disciplina de Linguagens e Tecnologias aplicadas ao Ensino, do Mestrado Acadêmico em Ensino de Humanidades e Linguagens, da Universidade Franciscana. O artigo está organizado em cinco seções. A primeira corresponde à introdução. A seguir apresenta-se as multimodalidades na prática docente. Em seguida, faz-se algumas reflexões sobre a temática do meio ambiente nas práticas pedagógicas, na sequência disserta-se sobre as orientações metodológicas e aplicações práticas. Por fim, as considerações finais.

\section{MULTIMODALIDADES NA PRÁTICA DOCENTE}

Hoje em dia existem muitas formas de comunicação possíveis e por esse motivo o ensino e a aprendizagem da leitura e da escrita precisam levar em conta o conceito da multimodalidade (ROJO, 2012). 
Nesse contexto, os professores precisam estar preparados para ensinar não apenas as habilidades técnicas, desses meios de comunicação, mas também a compreensão das diferentes modalidades e de suas características para que a produção de significado realmente aconteça.

Nas práticas sociais as pessoas se comunicam por meio de palavras, sinais, gestos e outros recursos semióticos, configurando a comunicação como um evento multimodal que agrega diversos recursos semióticos (VIEIRA; SILVESTRE, 2015). Os avanços tecnológicos determinam novas formas de interação entre as pessoas, utilizando a leitura, a escrita, imagens nas comunicações e informações, e isso resulta em novas demandas nas práticas docentes. A multimodalidade está presente na linguagem, seja ela oral ou escrita. E, a composição de textos multimodais se faz presente nas práticas sociais, sendo representados por cores, imagens, movimento, som e escrita (VIEIRA; SILVESTRE, 2015). Na contemporaneidade há uma exigência para que a escola forme leitores considerando os diversos elementos multimodais em diferentes modalidades discursivas.

O trabalho com a multimodalidade se caracteriza como uma ferramenta que favorece cada vez mais as práticas de ensino aprendizagem. Por outro lado, no fazer pedagógico o uso das novas tecnologias configura-se como um desafio para o professor. Masetto (2012) afirma que a inovação na educação é um conjunto de transformações que afeta as organizações do ensino geradas pelas mudanças do avanço tecnológico e da comunicação na sociedade. Em consonância com isso, Thompson (1998) expõe que a tecnologia exige do professor o conhecimento das consequências do seu uso, no desenvolvimento cognitivo e na formação social do educando.

Os impactos sociais do desenvolvimento das novas redes de comunicação modificam o fluxo de informação e conteúdo, e as relações entre os sujeitos. Essa ferramenta, em seu uso implica uma construção de novas formas de agir e interagir com o mundo social. Nesse viés, as mudanças do mundo globalizado ligados à vida social contemporânea fizeram com que a linguagem se adaptasse a essa nova realidade do mundo tecnológico. A linguagem se coloca como instrumento que se adapta a tecnologias, porém a mensagem principal é mantida em leituras do Facebook. O evento discursivo escrito já não representa exatamente o fato, pois já se tornou uma representação do discurso anterior representado, tornando-se assim uma segunda ordem de representação mais complexa que a primeira (HENDGES; NASCIMENTO, 2016).

Os textos multimodais têm alimentado as práticas sociais, os modos de representações utilizados incluem imagens, cores, movimentos, som e escrita. No entanto, Vieira e Silvestre (2015) argumentam que desse ponto de vista ser iletrado em linguagem visual denúncia vulnerabilidade social e baixo empoderamento do sujeito. Nessa perspectiva, é importante educar os cidadãos para que estes desenvolvam a capacidade de interpretar textos multimodais com maior discernimento.

Em nossas práticas sociais nos comunicamos não apenas por meio de palavras, mas também de sinais, gestos e imagens, entre outros recursos semióticos, configurando a comunicação como um evento multimodal que agrega diversos modos e recursos semióticos, independente do meio pela qual ela se realize [...] (BARBOSA, 2016, p. 625). 
A produção de um texto multimodal exige uma reflexão da mensagem transmitida, a partir daí quais representações visuais são mais adequadas para transmitir esta mensagem. A linguagem visual tem mais força na construção e manutenção do poder simbólico, porque a imagem corporifica o discurso, ela provoca sentimentos, emoção e afeto no leitor, direcionando sua atenção para o propósito do discurso (VIEIRA; SILVESTRE, 2015).

Sendo assim, pode-se dizer que o ensino está associado ao processo de comunicação e interação pelos quais os estudantes assimilam saberes, habilidades, técnicas existentes na sociedade (LIBÂNEO, 2010). O dia-a-dia da prática docente desafia o professor a reconstruir sua metodologia de ensino e ampliar seus conhecimentos, tornando-se um eterno aprendiz no seu desenvolvimento profissional. E, é preciso um tempo para sair da zona de conforto na busca da qualificação da docência, abandonar o paradigma tradicional de ensino e estabelecer o compromisso com a educação transformadora que atenda às novas demandas no campo educacional.

\section{MEIO AMBIENTE, PRÁTICAS PEDAGÓGICAS E SOCIEDADE}

A escolha da temática meio ambiente, considera a importância de falar sobre o meio ambiente tendo em vista que a sociedade está vivendo uma crise econômica e de valores éticos, e consequentemente, a degradação ambiental. O ensino básico tem de atender às novas demandas da sociedade contemporânea, nesse sentido frente aos problemas ambientais, os professores devem permear práticas pedagógicas que desenvolvam novas atitudes na relação homem e meio ambiente.

Nesse sentido, Angeloni (2010), fala que as escolas precisam se adequar às novas demandas da sociedade para dar conta da formação de alunos capazes de interagir no mundo de forma consciente. Na Base Nacional Comum Curricular (BNCC), está determinado que compete aos sistemas e às instituições de ensino, introduzirem, nos currículos e nas propostas pedagógicas, temas contemporâneos que afetam a sociedade. Entre esses temas, pode-se destacar a educação ambiental, que deve ser estudada de maneira transversal e integradora pelas diferentes áreas do conhecimento (BRASIL, 2018; RIBEIRO; BOER; COUTINHO, 2020). Em consonância às orientações das diretrizes da BNCC, o Referencial Curricular Gaúcho (RCG), no caderno Ciências da Natureza dispõe que as escolas gaúchas devem incluir nos currículos de ensino os temas contemporâneos, a fim de promover a formação integral do sujeito, a partir de um ensino que favoreça a compreensão da realidade social, dos direitos e responsabilidades do ser humano em relação à vida pessoal, social e ambiental (RIO GRANDE DO SUL, 2018; RIBEIRO; BOER; COUTINHO, 2020).

De acordo com Guimarães (2013), meio ambiente é um conjunto de elementos vivos ou não vivos que se relacionam, influenciando-se entre si, através de um equilíbrio dinâmico, que constituem o planeta terra. A partir do que estabelece a lei brasileira, a escola precisa promover a formação ambiental para seus educandos. Essas orientações buscam tornar a aprendizagem dos estudantes mais 
fácil e interessante, utiliza-se diversificados recursos metodológicos com enfoque na linguagem oral, escrita e visual. A linguagem visual tem mais força na construção e manutenção do poder simbólico, porque a imagem corporifica o discurso, ela provoca sentimentos, emoção e afeto no leitor, direcionando sua atenção para o propósito do discurso.

Os textos multimodais têm alimentado as práticas sociais, os modos de representações utilizados incluem imagens, cores, movimentos, som e escrita. No entanto, Vieira e Silvestre (2015) argumentam que, desse ponto de vista, ser iletrado em linguagem visual denúncia vulnerabilidade social e baixo empoderamento do sujeito. Sendo assim, é importante educar os cidadãos para que estes desenvolvam a capacidade de interpretar textos multimodais com maior discernimento.

O poder simbólico ou cultural chega aos estudantes por vias dos meios de informação e comunicação então, pode-se afirmar que é por meio da linguagem que conseguimos comunicar os nossos conhecimentos em um mundo permeado de sinais e símbolos. A linguagem interfere no comportamento das pessoas, onde há participação com semelhantes e a compreensão da realidade da vida cotidiana, gera-se comunicação como produto que terá como resultado o conhecimento (BERGER; LUCKMANN, 2003).

\section{ASPECTOS METODOLÓGICOS E APLICAÇÕES PRÁTICAS}

A metodologia apresenta uma abordagem qualitativa, de cunho bibliográfico. Minayo (2007, p. 10) esclarece que "[...] as metodologias de pesquisa qualitativa são [...] capazes de incorporar a questão do significado e da intencionalidade como inerentes aos atos, às relações e às estruturas sociais [...]". De acordo com GIL (2008), uma pesquisa bibliográfica está apoiada em materiais já elaborados, constituída principalmente de livros e artigos científicos.

Para realizar qualquer atividade com sucesso na vida é necessário planejar, programar, analisar certa realidade e a partir disso poder pensar intervenções para superar determinadas dificuldades, de modo especial, neste trabalho, considera-se o planejamento como um processo de análise e reflexão que visa a adquirir os objetivos da escola dentro de uma situação de aprendizagem (SCHMITZ, 1993; CORDEIRO, 2007; LIBÂNEO, 2009).

No que se refere ao planejamento didático, foi planejado para ser desenvolvido em três aulas na disciplina de Língua Portuguesa, tendo como objetivo geral que os estudantes do Ensino Médio, compreendam o conceito de meio ambiente e como específicos, discutir acerca das problemáticas ambientais; entender que as suas atitudes contribuem para a preservação ou degradação do meio ambiente; desenvolver a capacidade argumentativa; elaborar um resumo sobre a temática; construir um jogo didático de microconteúdo com memes, denominado "Meio Ambiente em Jogo".

Pensando na contribuição da representação oral e escrita, os alunos serão direcionados para o laboratório de informática onde deverão realizar a pesquisa sobre os conceitos de meio ambiente e das 
problemáticas ambientais. Dando sequência às atividades, na segunda aula ocorrerá uma roda de conversa acerca da pesquisa, neste momento os estudantes poderão expor suas dúvidas e conceitos encontrados, com o intuito de construírem um conhecimento em conjunto com relação à temática do meio ambiente.

A partir disso, os grupos devem redigir um resumo apresentando o resultado de suas respectivas pesquisas com fundamentação teórica. Além disso, o resumo será usado como roteiro para a construção do jogo didático de acordo com a proposta de aula. A avaliação do desempenho constará da presença, participação e envolvimento dos estudantes nas atividades propostas, configurando-se deste modo, como uma avaliação contínua. Os critérios avaliativos serão a preparação, organização, coerência, clareza na exposição de ideias, criatividade, resumo e a capacidade argumentativa.

Uma das aplicações realizadas para verificar se o planejamento daria conta dos objetivos ocorreu na turma na disciplina de Linguagens e Tecnologias aplicadas ao Ensino com os mestrandos. Foi construído um jogo no powerpoint em que se faziam perguntas do tipo "Meio ambiente é um conjunto de elementos vivos ou não vivos que se relacionam, influenciando-se entre si, através de um equilíbrio dinâmico, que constituem o planeta terra. A afirmativa está?" 1- Certa; 2- Errada. A partir das respostas dos alunos, ao clicar em uma das alternativas, era direcionado para outro slide que continha um meme representativo da resposta.

O uso das mídias digitais facilita o uso e a combinação de conteúdos, independente da sua versão original pois são capazes de traduzir de modo mais simpático o conteúdo informativo e assim a reflexão a respeito das contribuições do ensino de multimodalidades para a prática docente fica mais evidente.

\section{CONSIDERAÇÕES FINAIS}

Refletir acerca das contribuições do ensino de multimodalidades para a prática docente e apresentar um recorte do planejamento didático "Meio Ambiente em Jogo", proposto na disciplina de Linguagens e Tecnologias aplicadas ao Ensino, do Mestrado Acadêmico em Ensino de Humanidades e Linguagens, da Universidade Franciscana se constituiu como foco central deste estudo. O estudo realizado possibilitou a elaboração das considerações apresentadas a seguir:

Pensar sobre as práticas pedagógicas, quando seguidas de leituras, estudos e reflexões pode contribuir para uma formação permanente do professor centrada na razão comunicativa, crítica e emancipadora para os tempos contemporâneos. Diante das transformações tecnológicas que repercutem na prática docente, o professor precisa entender as contribuições que os usos de recursos multimodais oferecem para o processo de ensino aprendizagem.

Portanto, a formação docente deve ser desenvolvida considerando o contexto atual da sociedade, e nesta conjuntura o professor tem o papel de mediador, e a responsabilidade de trazer as múltiplas linguagens como objeto de discussão dentro de sua sala de aula para então promover o desenvolvi- 
mento do pensamento crítico junto dos alunos para que tenhamos aprendizados conscientes como reflexo do processo de ensino aprendizagem.

\section{REFERÊNCIAS}

ANGELONI, M. T. Comunicação nas organizações na era do conhecimento. São Paulo: Atlas, 2010.

BARBOSA, V.S. et al. Multimodalidade e multiletramentos: análise de atividades de leitura em meio digital. Revista Brasileira de Linguística Aplicada, v. 16, n. 4, p. 623-650, 2016.

BRAGA, J. L. ; CALAZANS, R. Comunicação e educação. São Paulo: Hacker Editores, 2001.

BRASIL. Ministério da Educação e Cultura. Base Nacional Comum Curricular, 2018. Disponível em: http://basenacionalcomum.mec.gov.br/. Acesso em: 02 mar. 2020.

BEHRENS, M.A. O paradigma emergente e a prática pedagógica. 5. ed. Petrópolis: Vozes, 2011.

BERGER, P. L.; LUCKMANN, T. A linguagem e o conhecimento na vida cotidiana. A construção social da realidade. Petrópolis, RJ: Vozes, p. 35-68, 2003.

CORDEIRO, J. Didática. São Paulo: Contexto, 2007.

GIL, A. C. Métodos e técnicas de pesquisa social. 6. ed. São Paulo: Atlas, 2008.

GUimarãeS, M. A. A dimensão ambiental na educação. 11. ed. Campinas, SP: Papirus, 2013. (Coleção Magistério: Formação e Trabalho Pedagógico

HENDGES, G. R.; NASCIMENTO, R. G. Convergências e desafios para a pesquisa com imagens em movimento sob a perspectiva da Análise do Discurso Multimodal. Letras. v. 26, n. 52, Santa Maria, RS: PPGL/UFSM, p. 25-47, 2016.

LIBÂNEO, J.C. Didática. São Paulo: Cortez Editora, 2009.

LIBÂNEO, J.C. Pedagogia e padagogos, para quê?. 12. ed. São Paulo: Cortez, 2010.

MASETTO, M.T. Inovação curricular no Ensino Superior. São Paulo: Loyola, 2012. 
MINAYO, M.C.S. O desafio do conhecimento: pesquisa qualitativa em saúde. SP: Hucitec, 2007.

RIBEIRO, C. S; BOER, N. COUTINHO, C. Marcos regulatórios e pressupostos teóricos da educação ambiental: um estudo de revisão bibliográfica. Research, Society and Development, v. 9, n. 3, e148932563, 2020.

RIO GRANDE DO SUL. Secretaria de Estado da Educação. Departamento Pedagógico. União Nacional dos Dirigentes Municipais de Educação. Referencial Curricular Gaúcho: Ciências da Natureza. Porto Alegre: Secretaria da Educação, Departamento Pedagógico, 2018. v. 1.

ROJO, R.; MOURA, E. (Orgs.). Multiletramentos na escola. São Paulo: Parábola, 2012.

SCHMITZ, E. Fundamentos da Didática. São Leopoldo: Unisinos, 1993.

THOMPSON, J. B. A mídia e a modernidade: uma teoria social da mídia. Petrópolis, RJ: Vozes, 1998.

VIEIRA; J. A.; SILVESTRE, C. Introdução à multimodalidade: contribuições da Gramática Sistêmico-Funcional, Análise de Discurso Crítica, Semiótica Social. Brasília, DF: UNB, 2015. 